\title{
Martian dust storms as a possible sink of atmospheric methane
}

\author{
W. M. Farrell, ${ }^{1}$ G. T. Delory, ${ }^{2}$ and S. K. Atreya ${ }^{3}$ \\ Received 12 June 2006; revised 15 August 2006; accepted 31 August 2006; published 10 November 2006.
}

[1] Recent laboratory tests, analog studies and numerical simulations all suggest that Martian dust devils and larger dusty convective storms generate and maintain large-scale electric fields. Such expected E-fields will have the capability to create significant electron drift motion in the collisional gas and to form an extended high energy $(u \gg k T)$ electron tail in the distribution. We demonstrate herein that these energetic electrons are capable of dissociating any trace $\mathrm{CH}_{4}$ in the ambient atmosphere thereby acting as an atmospheric sink of this important gas. We demonstrate that the methane destruction rate increases by a factor of $10^{12}$ as the dust storm E-fields, E, increase from 5 to $25 \mathrm{kV} / \mathrm{m}$, resulting in an apparent decrease in methane stability from $\sim 10^{10}$ sec to a value of $\sim 1000$ seconds. While destruction in dust storms is severe, the overall methane lifetime is expected to decrease only moderately due to recycling of products, heterogeneous effects from localized sinks, etc. We show further evidence that the electrical activity anticipated in Martian dust storms creates a new harsh electro-chemical environment. Citation: Farrell, W. M., G. T. Delory, and S. K. Atreya (2006), Martian dust storms as a possible sink of atmospheric methane, Geophys. Res. Lett., 33, L21203, doi:10.1029/ 2006GL027210.

\section{Introduction}

[2] The discovery of trace amounts of methane in the Martian atmosphere [Formisano et al., 2004; Krasnopolsky et al., 2004; Mumma et al., 2004] has generated great excitement in the Mars science community. While geological origin of methane is an attractive possibility [Formisano et al., 2004; Atreya et al., 2004; Oze and Sharma, 2005; Atreya et al., 2006a], there is a non-unique likelihood that the methane source is biogenic in nature [Chapelle et al., 2002; Krasnopolsky et al., 2004; Atreya et al., 2004, 2006a]. To date, the primary atmospheric loss processes considered for methane are through photochemistry and surface effects, with methane photochemical stability estimated to be on the order of several hundreds of years [Summers et al., 2002; Wong et al., 2003]. Such relatively long lifetimes suggest that any methane might become well-mixed in the Martian atmosphere. In this work, we introduce a second possible very active methane loss process: direct electron dissociation of methane in the high E-field environments expected in Martian dust devils, larger convective dust storms, and dust fronts. This highly

\footnotetext{
${ }^{1}$ NASA Goddard Space Flight Center, Greenbelt, Maryland, USA.

${ }^{2}$ Space Sciences Laboratory, University of California, Berkeley, California, USA

${ }^{3}$ Department of Atmospheric, Ocean and Space Sciences, University of Michigan, Ann Arbor, Michigan, USA.
}

Copyright 2006 by the American Geophysical Union. 0094-8276/06/2006GL027210 seasonal and quasi-local loss process could play a role in the non-uniformity of methane on the planet.

[3] Dust storms on Mars are expected to generate and maintain large-scale electric dipole fields, with interior E-field values approaching the atmospheric breakdown levels of $\sim 25 \mathrm{kV} / \mathrm{m}$ [Melnik and Parrot, 1998; Farrell et al., 2003, 2006; Zhai et al., 2006]. The E-fields form via grain-grain contact electrification that tends to leave smaller dust particles with a net negative charge and larger sandy grains with a net positive charge [Ette, 1971]. Vertical winds in the storm then mass-stratify (and charge-stratify) the grain distribution as a function of height, creating a downwarddirected electric dipole moment and large-scale dipole electric field structure [Crozier, 1964; Farrell et al., 2004].

[4] Evidence for this charge creation/separation process is in the form of analytical models [Melnik and Parrot, 1998; Farrell et al., 2003, 2006; Zhai et al., 2006] and terrestrial analog studies [Freier, 1960; Crozier, 1964; Schmidt et al., 1998; Delory et al., 2002; Farrell et al., 2004; Jackson and Farrell, 2006]. The former modeling studies all suggest that E-fields at many tens of $\mathrm{kV} / \mathrm{m}$ can be generated in a convective Martian storm with charging exponential growth time scales on the order of 10's of seconds under ideal conditions. The latter analog studies consistently find relatively large electric fields in small terrestrial dust devils and saltating dust fronts, with dust devil fields $>100 \mathrm{kV} / \mathrm{m}$ and dust front fields $>150 \mathrm{kV} / \mathrm{m}$. The E-fields in terrestrial dust devils/fronts are not large enough to create atmospheric breakdown on Earth, but well above the atmospheric breakdown fields of $\sim 25 \mathrm{kV} / \mathrm{m}$ for the low-pressure Martian atmosphere. Given that very similar analogous aeolian processes occur on Mars, large fields approaching breakdown are anticipated in that planet's dust devils/storms and dust frontal systems.

[5] A complementary set of papers by Delory et al. [2006] and Atreya et al. [2006b] recently examined the behavior of ambient electrons in the Martian atmosphere under the influence of large E-fields (like that in dust devils/ storms/fronts). They found that the electrons evolve in three ways: First, the electron density increases geometrically with increasing $\mathrm{E}$, this due to increasing $\mathrm{CO}_{2}$ ionizations from energetic E-field driven electrons. Second, the electron drift velocity steadily increases with E reaching $5 \times 10^{5} \mathrm{~m} / \mathrm{s}$ near $20 \mathrm{kV} / \mathrm{m}$. Finally, a distinct high energy electron tail develops in the electron distribution, with its power-law rolloff in the 10's of eVs decreasing directly with increasing E [Nighan, 1970; Delory et al., 2006]. Basically, a collisional plasma develops in a mature dust devil/storm in the low pressure $\mathrm{CO}_{2}$ atmosphere. This plasma may even glow [Eden and Vonnegut, 1973; Farrell et al., 2005].

[6] As described by Delory et al. [2006] and Atreya et al. [2006b], the energetic electrons also affect the ambient molecules in the low pressure gas. Specifically, electron dissociation of $\mathrm{CO}_{2}$ into $\mathrm{CO}$ and $\mathrm{O}^{-}$occurs near $4.4 \mathrm{eV}$. 


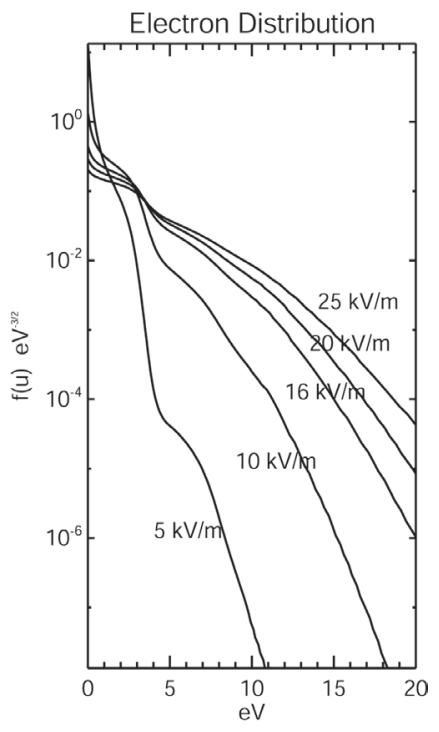

Figure 1. Electron distribution in the collisional $\mathrm{CO}_{2}$ atmosphere for E-fields at Martian atmospheric pressures.

Without the E-field, the electrons do not possess the intrinsic energy to dissociate the molecule. However, with an electric field, an energetic portion of the electron population now exists (i.e., the tail of the distribution) with the required energy to dissociate the $\mathrm{CO}_{2}$ and this population (between 4 and $5 \mathrm{eV}$ ) is found to increase geometrically with increasing E. Water also undergoes a similar electron dissociation attachment at a number of resonant energies between 6 and $12 \mathrm{eV}$ (the narrow resonance at $6.6 \mathrm{eV}$ is dominant), and Delory et al. [2006] found that the production of dissociated water products $\mathrm{OH}$ and $\mathrm{H}^{-}$also geometrically increases with increasing E-field. Atreya et al. [2006b] examined the subsequent recombination pathways for the dust storm E-field created species $\mathrm{CO}, \mathrm{O}^{-}, \mathrm{OH}$, and $\mathrm{H}^{-}$in the Martian near-surface atmosphere and found that anomalously large amounts of the reactive species $\mathrm{H}_{2} \mathrm{O}_{2}$ can be created in the atmosphere at concentrations exceeding 200 times that of regular photochemical production. The reactive product $\mathrm{H}_{2} \mathrm{O}_{2}$ was found to be at condensation levels and hence they conclude that the peroxide coats aeolian dust and the surface, and may possibly account for the presumed highly-reactive soil found by the Viking landers [Oyama et al., 1977].

[7] These tandem models suggest that the atmospheric conditions in Martian dust devils/storms/fronts are relatively harsh, with large E-fields, the creation of a collisional plasma (energetic electrons, $\mathrm{CO}_{2}^{+}$, and negative ions), and the formation of reactive species. Given this new meteorologydriven electrochemical environment on Mars that is so very different from the fair-weather photochemical environment, we ask an obvious question: What is the stability of methane in Martian dust storms?

\section{Model and Results}

[8] The behavior of electrons in a low pressure $\mathrm{CO}_{2}$ gas requires the solution of the Boltzmann equation with inclusion of inelastic and elastic collisions. The resulting electron distribution has been derived by Nighan [1970] and Delory et al. [2006] with similar results. Figure 1 shows the distribution from Delory et al. [2006] for the case of electrons in the Mars near-surface atmosphere. Note the development of an extended high energy electron tail (energy, $\mathrm{u}>4 \mathrm{eV}$ ) that increases in population with increasing E-field.

[9] The electron impact ionization of $\mathrm{CO}_{2}$ occurs for those electrons with energies, $\mathrm{u}>14 \mathrm{eV}$. Each impact will create an added electron thereby allowing exponential growth in electrons density defined by:

$$
\mathrm{n}_{\mathrm{e}}=\mathrm{n}_{\mathrm{eo}} \exp (\alpha \mathrm{x})
$$

where $\alpha$ is Townsend's first ionizing coefficient (in units of inverse length) and $\mathrm{x}$ is an anode/cathode distance (or separation of the charging centers). The inverse of $\alpha$ represents the distance required for an electron to impactionize $\mathrm{CO}_{2}$ thereby freeing a second electron. As quantified by Delory et al. [2006, equations 7 and 8 and Figure 4], this distance ranges from $10^{10} \mathrm{~cm}$ for fields at $5 \mathrm{kV} / \mathrm{m}$ to $3 \mathrm{~cm}$ at $25 \mathrm{kV} / \mathrm{m}$. We note that expression (1) applies for E-fields in pre-breakdown conditions. To consider discharges/full breakdown situations, a denominator term of the form $(1-F(\omega))$ would then be included in (1), where $F(\omega)$ is a function dependent upon the number of secondary electrons produced per unit length, $\omega$. Note that when enough secondaries are produced to have $1-F(\omega)=0$, the electron density becomes infinite, signifying complete breakdown of the gas. Since any modeled secondary processes is not unique and would create an unnecessary contrivance, we simply exclude breakdown/discharge situations in our model ( $\operatorname{set} F(\omega)=0$ ), and consider our formalism in (1) as applicable to the pre-breakdown electrostatic environment in the dust devil.

[10] The energetic electrons are also capable of dissociating $\mathrm{CO}_{2}$ at energies near $4.4 \mathrm{eV}$ [Delory et al., 2005]. At this resonance, an electron will dissociate $\mathrm{CO}_{2}$ into $\mathrm{CO}$ and $\mathrm{O}-$. The production of $\mathrm{CO} / \mathrm{O}-$ is describable via

$$
\mathrm{dn}_{\mathrm{CO} / \mathrm{O}-} / \mathrm{dt}=\mathrm{k}_{\mathrm{e} / \mathrm{CO} 2} \mathrm{n}_{\mathrm{CO} 2} \mathrm{n}_{\mathrm{e}}
$$

where $\mathrm{k}_{\mathrm{e} / \mathrm{CO} 2}$ is the chemical rate for the reaction and $\mathrm{n}$ is the density of the designated species. The chemical rate is [Ferreira, 1983]

$$
\begin{aligned}
\mathrm{k}_{\mathrm{e} / \mathrm{CO} 2}= & \left\langle\sigma_{\mathrm{d}} \mathrm{v}\right\rangle=\left(2 \mathrm{e} / \mathrm{m}_{\mathrm{e}}\right)^{1 / 2} \int_{\mathrm{u}_{\mathrm{o}}-\mathrm{du} / 2}^{\mathrm{u}_{\mathrm{o}}+\mathrm{du} / 2} \sigma_{\mathrm{d}}(\mathrm{u}) \mathrm{uf}(\mathrm{u}) \mathrm{du} \\
& \sim\left(2 \mathrm{e} / \mathrm{m}_{\mathrm{e}}\right)^{1 / 2} \sigma_{\mathrm{d}}\left(\mathrm{u}_{\mathrm{o}}\right) \mathrm{u}_{\mathrm{o}} \mathrm{f}\left(\mathrm{u}_{\mathrm{o}}\right) \delta \mathrm{u}
\end{aligned}
$$

where $\sigma_{\mathrm{d}}$ is the $\left(\mathrm{e}, \mathrm{CO}_{2}\right)$ dissociation cross section of $\sim 0.15 \times 10^{-22} \mathrm{~m}^{2}$ [Itakawa, 2002], at $\mathrm{u}_{\mathrm{o}}$ of $4.4 \mathrm{eV}$ and $\delta \mathrm{u}$ is the relatively-narrow cross section width of $\sim 1.0 \mathrm{eV}$. We make use of the narrow line width to derive the approximate form of k in (3). Delory et al. [2006] found that the E-field production of $\mathrm{CO} / \mathrm{O}^{-}$ranged from $10^{10} \mathrm{~m}^{-3} \mathrm{~s}^{-1}$ at $5 \mathrm{kV} / \mathrm{m}$ to $\sim 10^{18} \mathrm{~m}^{-3} \mathrm{~s}^{-1}$ at $25 \mathrm{kV} / \mathrm{m}$. A similar calculation was made therein for $\left(\mathrm{e}, \mathrm{H}_{2} \mathrm{O}\right)$, and subsequent products $\mathrm{OH} / \mathrm{H}^{-}$were found to be at $10^{7} \mathrm{~m}^{-3} \mathrm{~s}^{-1}$ at $5 \mathrm{kV} / \mathrm{m}$ to $\sim 10^{15} \mathrm{~m}^{-3} \mathrm{~s}^{-1}$ at $25 \mathrm{kV} / \mathrm{m}$ (for a water loss $\Delta \mathrm{n} / \mathrm{n}$ of $\sim 10^{-5}$ every second in large fields). As described in the complementary paper of Atreya et al. [2006b], the enhanced production of $\mathrm{O}$ and $\mathrm{H}$ 


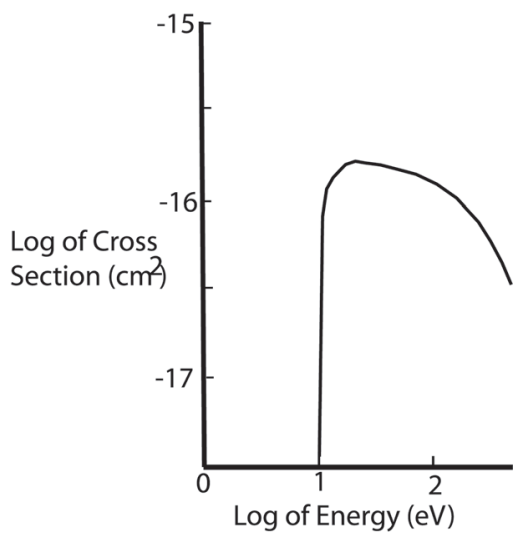

Figure 2. Cross section for electron dissociation of $\mathrm{CH}_{4}$ (data from Ohmori et al. [1986]).

in large E-fields was used as inputs to an atmospheric chemistry model which found that for large electric fields the atmospheric abundance of the recombination product $\mathrm{H}_{2} \mathrm{O}_{2}$ may exceed 200 times that of maximum photochemical model, with column density values of $\mathrm{H}_{2} \mathrm{O}_{2}$ at $7 \times 10^{17} \mathrm{~cm}^{-2}$ and intermediate product $\mathrm{OH}$ at $8 \times 10^{13} \mathrm{~cm}^{-2}$ [Atreya et al., 2006b]. This enhancement of the peroxide has implications in the biogeochemistry of Mars soil/surface (see discussion therein). Clearly, the electro-chemistry model indicates that the collisional plasma that forms in dust storms is a harsh electrochemical environment creating very reactive species via subsequent recombination of electron-dissociated products.

[11] Energetic electrons are also capable of dissociating methane at energies $>10 \mathrm{eV}$. Figure 2 shows the methane

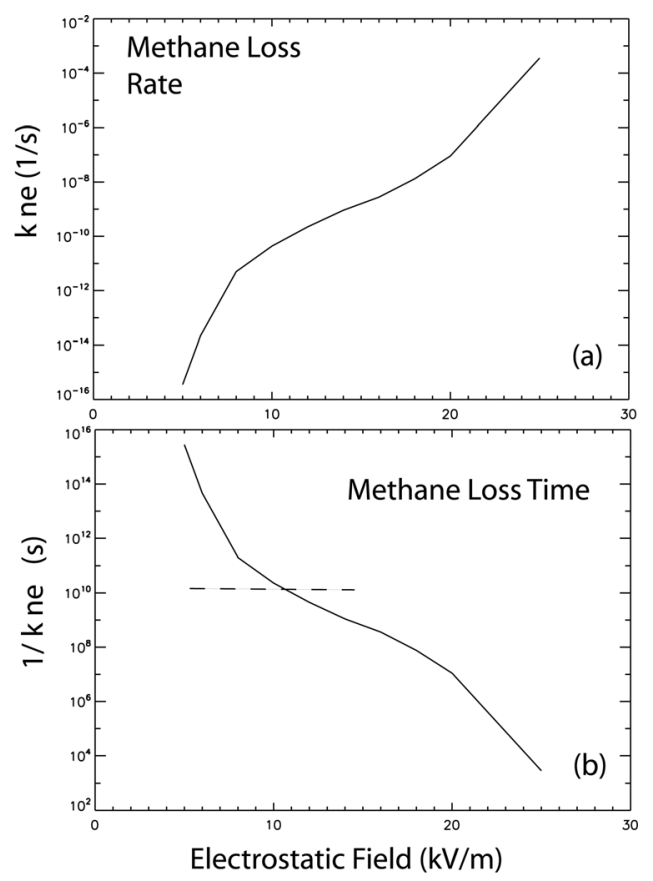

Figure 3. Methane destruction rate and destruction time as a function of storm electrostatic field. Note that the loss time drops from $>300$ year $\left(\sim 10^{10} \mathrm{sec}\right)$ to less than 1000 seconds in storms with large E-fields. dissociation cross section (adapted from Ohmori et al. [1986]). Unlike $\mathrm{CO}_{2}$ and $\mathrm{H}_{2} \mathrm{O}$, the methane dissociation cross section is relatively broad, starting near $10 \mathrm{ev}$, peaks at $20 \mathrm{eV}$, and slowly decreasing beyond $100 \mathrm{eV}$. The methane loss via electron dissociation can be described via

$$
\mathrm{dn}_{\mathrm{CH} 4} / \mathrm{dt}=-\mathrm{k}_{\mathrm{e} / \mathrm{CH} 4} \mathrm{n}_{\mathrm{CH} 4} \mathrm{n}_{\mathrm{e}}
$$

where

$$
\mathrm{k}_{\mathrm{e} / \mathrm{CH} 4}=\left\langle\sigma_{\mathrm{d}} \mathrm{v}\right\rangle=\left(2 \mathrm{e} / \mathrm{m}_{\mathrm{e}}\right)^{1 / 2} \int_{0}^{\infty} \sigma_{\mathrm{d}}(\mathrm{u}) \mathrm{u} \mathrm{f}(\mathrm{u}) \mathrm{du}
$$

where $\sigma_{\mathrm{d}}(\mathrm{u})$ is the methane dissociation cross section shown in Figure 2 and $\mathrm{f}(\mathrm{u})$ is shown in Figure 1. The electron density is defined by equation (1) and we assume that the ambient density of $\mathrm{CH}_{4}$ is $\mathrm{n}_{\mathrm{CH} 4} \sim 10 \mathrm{ppb} \sim 2 \times 10^{15} \mathrm{~m}^{-3}$.

[12] Figure 3 shows the destruction of methane (Figure 3a) and methane destruction time $\left(\left(\mathrm{k}_{\mathrm{e} / \mathrm{CH} 4} \mathrm{n}_{\mathrm{e}}\right)^{-1}\right)$ (Figure $3 \mathrm{~b}$ ) as a function of dust devil/storm/front electric field. The line in Figure $3 \mathrm{~b}$ indicates the photochemical lifetime of $10^{10}$ seconds $(\sim 300$ years $)$. Note that as the E-field increases, the $\mathrm{CH}_{4}$ destruction time geometrically decreases and is close to $\sim 1000$ seconds for large E-fields (Figure 4).

\section{Conclusions}

[13] The meteorological-driven electrochemical environment in dust devils/storms/fronts is a clear sink of atmospheric methane. The molecular destruction time of methane exponentially decreases with driving electric field as $\mathrm{t}(\mathrm{E}) \sim \mathrm{t}_{\mathrm{o}} \exp \left(-\beta\left(\mathrm{E}-\mathrm{E}_{\mathrm{o}}\right)\right)$ where $\mathrm{t}_{\mathrm{o}}$ is $10^{11}$ seconds, $\mathrm{E}_{\mathrm{o}}$ is $10 \mathrm{kV} / \mathrm{m}$ and $\beta$ is $1.2 \times 10^{-3} \mathrm{~m} / \mathrm{kV}$. The value of $1 / \beta$ represents an e-folding of the value of t every $\sim 1 \mathrm{kV} / \mathrm{m}$. We note that the global methane lifetime, even with dust storm losses, may only display a moderate decrease since we have not included sources from recycling of dissociated products back into $\mathrm{CH}_{4}$, including but not limited to such unexplored processes as reactions between energetic (hot) hydrogen atoms and methyl radicals, heterogeneous chemistry, atmospheric dynamics, etc. Also, the volumetric regions of largest E-fields still remained undefined for Mars. Once

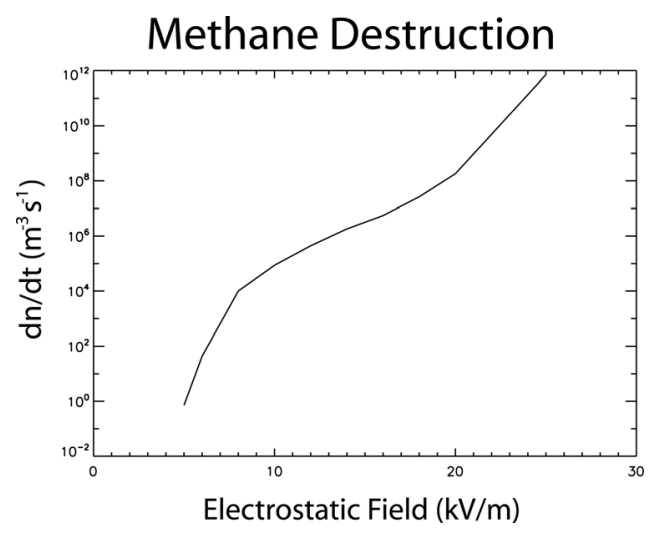

Figure 4. Methane destruction as a function of electrostatic field, assuming methane concentrations at $10 \mathrm{ppb}$. 
these elements of the problem become known, a new largescale lifetime can be derived.

[14] It has been proposed (via the Mars Scout program) to fly a high resolution atmospheric composition spectrometer from orbit specifically targeting the sources and sinks of methane. Given the results herein, such an orbiting spectrometer should see temporal and spatial variations in $\mathrm{CH}_{4}$ in association with dust activity. At the largest time and spatial scales, we suggest that the global content of methane may have a seasonal dependence, with abundance being smaller during and immediately following the major dust storm season (just after southern summer), depending upon how fast methane recovers. On intermediate temporal/spatial scales (weeks $/ 100 \mathrm{~s} \mathrm{~km})$, it is anticipated that methane concentrations will decrease in spatial regions behind dust fronts and in the near-vicinity of the dusty "cores" that form in the southern highlands in southern summer, just prior to the onset of major dust storms. Mesoscale missions that examine atmospheric composition in a region (i.e., airplane, balloon) should observe a correlation between passing dust storms and fronts, E-fields, and methane production. On the small temporal/spatial scales (10's minutes $/ \sim 1 \mathrm{~km}$ ), methane concentrations are anticipated to decrease at locations of local dust devil activity. This smallest scale might not be resolvable via orbiting spectrometers. However, landed assets such as the mass spectrometer and the tunable laser spectrometer that are part of the Sample Analysis at Mars (SAM) suite on the 2009 Mars Science Laboratory (MSL) are expected to note some decrease in methane with the passing of a moderate sized dust devil (lasting a few minutes) or in conjunction with a set of dust devils like that recently observed passing in succession by MER (http:// marsrovers.jpl.nasa.gov/gallery/press/spirit/20050819a/ dd_enhanced_568b-B558R1.gif). Laboratory simulation studies and further modeling are required to fully characterize the effect of electric fields on the nature of methane on Mars.

[15] Acknowledgments. The authors are grateful to their sponsored funding sources for this research: W.M.F. and G.T.D. are supported by NASA's Mars Fundamental Research Program and S.K.A. is supported by NASA's Mars Express and Mars Science Laboratory Mission programs.

\section{References}

Atreya, S. K., T. Encrenaz, V. Formisano, and A. S. Wong (2004), Methane on Mars: sources, sinks, and implications for life, paper presented at International Mars Conference, Ital. Space Agency, Ischia, Italy.

Atreya, S. K., P. R. Mahaffy, and A. S. Wong (2006a), Methane and related trace species on Mars-Origin, loss, implications for life, and habitability, Planet. Space Sci, in press.

Atreya, S. K., et al. (2006b), Oxidant enhancement in Martian dust devils and storms: implications for life and habitability, Astrobiology, 6, 439.

Chapelle, F. H., et al. (2002), A hydrogen-based subsurface microbial community dominated by methanogens, Nature, 415, 312 .

Crozier, W. D. (1964), The electric field of a New Mexico dust devil, J. Geophys. Res., 69, 5427.

Delory, G. T., et al. (2002), The electrical structure of terrestrial dust devils: Implications of multiple vertical measurements of the electric field, Eos Trans. $A G U, 83(47)$, Fall Meet. Suppl., Abstract P51A-0335.

Delory, G. T., et al. (2006), Oxidant enhancement in Martian dust devils and storms: Storm electric fields and electron dissociative attachment, Astrobiology, 6, 451 .
Eden, H. F., and B. Vonnegut (1973), Electrical breakdown cause by dust motion in low pressure atmospheres: Consideration for Mars, Science, $180,962$.

Ette, A., II (1971), The effect of Hermattian dust on atmospheric electric parameters, J. Atmos. Terr. Phys., 33, 295.

Farrell, W. M., G. T. Delory, S. A. Cummer, and J. R. Marshall (2003), A simple electrodynamic model of a dust devil, Geophys. Res. Lett., 30(20), 2050, doi:10.1029/2003GL017606.

Farrell, W. M., et al. (2004), Electric and magnetic signatures of dust devils from the 2000-2001 MATADOR desert tests, J. Geophys. Res., 109, E03004, doi:10.1029/2003JE002088.

Farrell, W. M., et al. (2005), Martian dust devil and storm electric fields: The formation of an O- plasma and new local chemistry, EOS Trans. $A G U, 86(52)$, Fall Meeting Suppl., Abstract P13B-0150.

Farrell, W. M., N. Renno, G. T. Delory, S. A. Cummer, and J. R. Marshall (2006), Integration of electrostatic and fluid dynamics within a dust devil, J. Geophys. Res., 111, E01006, doi:10.1029/2005JE002527.

Ferreira, C. M. (1983), Current research topics in low-pressure glow discharges in rare gases and in pure nitrogen, in Electrical Breakdown and Discharges in Gases, Part A: Fundamental Processes and Breakdown, edited by E. E. Kunhardt and L. H. Luessen, p. 395, Springer, New York.

Formisano, V., S. K. Atreya, T. Encrenaz, N. Ignatiev, and M. Giuranna (2004), Detection of methane in the atmosphere of Mars, Science, 306, 1758

Freier, G. D. (1960), The electric field of a large dust devil, J. Geophys. Res., 65, 3504.

Itakawa, Y. (2002), Cross sections for electron collisions with carbon dioxide, J. Phys. Chem. Ref. Data, 31, 749.

Jackson, T. J., and W. M. Farrell (2006), Electrostatic fields in dust devils: Analog to Mars, IEEE Trans. Geosci. Remote Sens., 44, 2942-2949.

Krasnopolsky, V. A., J. P. Maillard, and T. C. Owen (2004), Detection of methane in the Martian atmosphere: Evidence for life?, Icarus, 172, 537.

Llewellyn-Jones, F. (1981), The development of theories of the electrical breakdown of gases, in Electrical Breakdown and Discharges in Gases, Part A: Fundamental Processes and Breakdown, edited by E. E. Kunhardt and L. H. Luessen, p. 1, Springer, New York.

Melnik, O., and M. Parrot (1998), Electrostatic discharge in Martian dust storms, J. Geophys. Res., 103, 29,107.

Mumma, M. J., et al. (2004), Detection and mapping of methane and water on Mars, Bull. Am. Astron. Soc., 36(4), Abstract 26.02.

Nighan, W. L. (1970), Electron energy distributions and collision rates in electrically excited $\mathrm{N}_{2}, \mathrm{CO}$, and $\mathrm{CO}_{2}$, Phys. Rev. A, 2, 1989.

Ohmori, Y., et al. (1986), Boltzmann equation analysis of electron swarm behavior in methane, J. Phys. D, 19, 437-455.

Oyama, V. I., et al. (1977), Preliminary findings of the Viking gas exchange experiment and a model for Martian surface chemistry, Nature, 265, 100.

Oze, C., and M. Sharma (2005), Have olivine, will gas: Serpentinization and the abiogenic production of methane on Mars, Geophys. Res. Lett., 32, L10203, doi:10.1029/2005GL022691.

Schmidt, D. A., et al. (1998), Electrostatic forces on saltating sand, J. Geophys. Res., 103, 8997.

Summers, M. E., B. J. Lieb, E. Chapman, and Y. L. Yung (2002), Atmospheric biomarkers of subsurface life on Mars, Geophys. Res. Lett., 29(24), 2171, doi:10.1029/2002GL015377.

Wong, A., S. K. Atreya, and T. Encrenaz (2003), Chemical markers of possible hot spots on Mars, J. Geophys. Res., 108(E4), 5026 , doi:10.1029/2002JE002003. (Correction and updated reaction, J. Geophys. Res., 110, E10002, doi:10.1029/2005JE,002509, 2005.)

Zhai, Y., S. A. Cummer, and W. M. Farrell (2006), Quasi-electrostatic field analysis and simulation of Martian and terrestrial dust devils, J. Geophys. Res., 111, E06016, doi:10.1029/2005JE002618.

S. K. Atreya, Department of Atmospheric, Ocean and Space Sciences, University of Michigan, 2455 Hayward Street, Ann Arbor, MI 48109-2143, USA.

G. T. Delory, Space Sciences Laboratory, University of California, MS 7450, Berkeley, CA 94720-0000, USA.

W. M. Farrell, NASA Goddard Space Flight Center, Code 695, Greenbelt, MD 20771, USA. (william.farrell@gsfc.nasa.gov) 